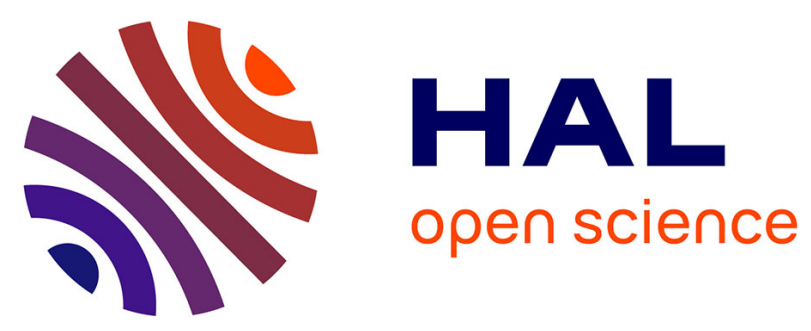

\title{
Development of a laser shock adhesion test for the assessment of weak adhesive bonded CFRP structures
}

Bastien Ehrhart, Romain Ecault, Fabienne Touchard, Michel Boustié, Laurent Berthe, Clemens Bockenheimer, Bernd Valeske

\section{- To cite this version:}

Bastien Ehrhart, Romain Ecault, Fabienne Touchard, Michel Boustié, Laurent Berthe, et al.. Development of a laser shock adhesion test for the assessment of weak adhesive bonded CFRP structures. International Journal of Adhesion and Adhesives, 2014, 52, pp.57-65. 10.1016/j.ijadhadh.2014.04.002 . hal-01059299

\section{HAL Id: hal-01059299 \\ https://hal.science/hal-01059299}

Submitted on 29 Aug 2014

HAL is a multi-disciplinary open access archive for the deposit and dissemination of scientific research documents, whether they are published or not. The documents may come from teaching and research institutions in France or abroad, or from public or private research centers.
L'archive ouverte pluridisciplinaire HAL, est destinée au dépôt et à la diffusion de documents scientifiques de niveau recherche, publiés ou non, émanant des établissements d'enseignement et de recherche français ou étrangers, des laboratoires publics ou privés. 


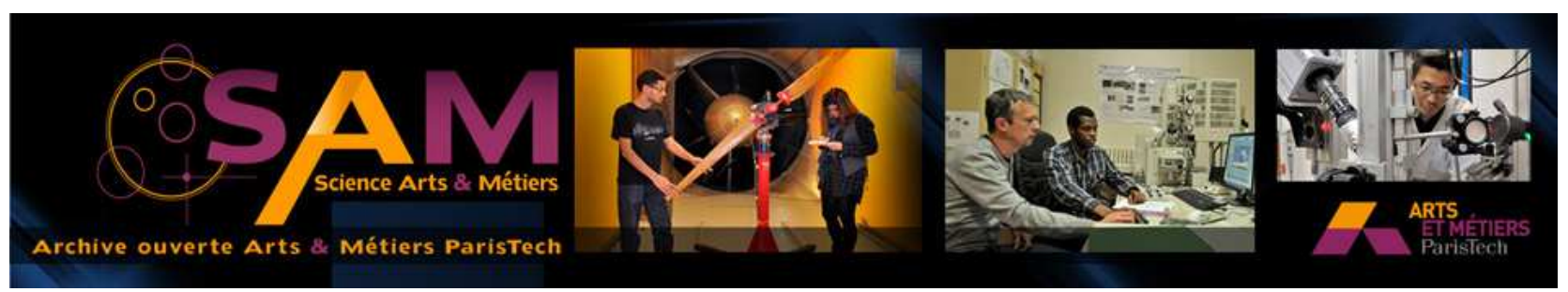

\section{Science Arts \& Métiers (SAM)}

is an open access repository that collects the work of Arts et Métiers ParisTech researchers and makes it freely available over the web where possible.

This is an author-deposited version published in: http://sam.ensam.eu

Handle ID: .http://hdl.handle.net/10985/8417

\section{To cite this version :}

Bastien EHRHART, Romain ECAULT, Fabienne TOUCHARD, Michel BOUSTIE, Laurent BERTHE, Clemens BOCKENHEIMER, Bernd VALESKE - Development of a laser shock adhesion test for the assessment of weak adhesive bonded CFRP structures - International Journal of Adhesion \& Adhesives - Vol. 52, p.57-65 - 2014 


\title{
Development of a laser shock adhesion test for the assessment of weak adhesive bonded CFRP structures
}

\author{
Bastien Ehrhart a.Romain Ecault b., Fabienne Touchard b, Michel Boustie b.Laurent Berthe c, \\ Clemens Bockenheimer d, Bemd Valeske a \\ -Fraunhofer Instituœfor Non-Destnu:tllf! Test Method.s (rZFP). Saatfnuedcm, Gmnat!\} \\ blnstftut Pprlme. CNRS-f.NSMA-Untllm(tl de Poitiers. Dlparœment Pflyslq et Mkanlque des Math1aulc -F.NSMA. Pofltm. fnmc:'e \\ $<$ PIMM, CNfiS..ENSilM Paristedt,. Furis, fnmc:'e \\ ${ }^{4}$ Airflu.s Openztions $\mathrm{GmbH}$, Bmn.en. Gemum.)'
}

Keywords:

Adhesive joints

Debondiug

Impact behavior

Damage toler.uKe

\begin{abstract}
Adhesive bondin,g bas a great poœnlial far future ligbtweight bigb-loaded structures in the a.eronautic industiy. A preœquisite for sucb an application is dtat the bond quality of the adhesive joint can be assessed in a non-destructive way. However, the use of da.ssicaJ Non-DesiiUctive Techniques (NDT) does not aUow the evaluation of the adhesion stren,gt:h of an adhesive bond yet This paper pn!sents an investigation made on weak composite bonds in on ler to develop a laser shock wave adhesion test First, the procedure to produce controlled weak bonds is desaibed. CFRP bonded samples are pn!pared in a spedfic way and characterized by ultrasonic techniques to assess the absence of any detectable defect. 1 ben, for sorne of the .samples, their bond streDgth is evaluated by mechanical destructive œsts and ether .samples are loaded by v.arious intensity lasers shocks. The obtained results help to understand the behavior of the composite bonds under Jaser shock loading:. thanks to two post-mortem techrùques. 1 becorrelation between the laser parameterS and the induced damage is demon.strated, The potential of the laser shock. technique to dl.saiminate different bond quallties is shawn, and the need for the œst optinùzationlsd $\hat{U}(\mathrm{U}$
\end{abstract}

\section{Intloduc:tfon}

Adhesive bonding is for many reasons an assembly method with a pronùsing future. Its advantages over other assembly processes are numerous: a homogeneous stress distribution due to the absence of fastening elements, a welght saving induced by this absence, an increase of structure fatigue resistance and the ability tD join distinct substraœs while acting as a corrosion protection or insulating layer. This teclmology bas a high potential for the applications of tomorrow, especially with the increasing use of llght composite structures [1.2).A or limitation tD the rapid extension of this technology is œrtainly due tD the difficuJty in achieving non-destructive assessment of the adhesion quatity. The process of adhesive bonding is very sensitive and the adhesive bond performance is easily affected by significant deviations so that weak adhesive bonds are stiJl to be considered as a major banier to the development of structural adhesive bonding (3).The literature staœs that even if physic.al defects \{ porosity, debonding, cracks, etc.) can dearly be detected in adhesive joints of composites by use of Non-Destructive Testing (NDT) methods, no statements can be made regarding the quality of the adhesion. its strength or its properties (4-7).1ndeed. no evaluation of the bond perfonnances and by extension no characterization of weak adhesive bonds is yet available by any NDT method. Based on this observation, a novel approach bas been Introduced over the last years: 'E:xtended NOT methods are being developed tD be able to assess the performances of adhesive bonds (8-11).Among the Extended NDT methods, two fields of application exist: the characterization of adhenmt surface prior to bonding operation wlùch is belng investigated with technologies such as portable FT-IR spectrometry, portable X-Ray fluorescence, or even the aerosol wetting test $[11,12)$; the second application field concerns the investigation of the adhesive bondline after the bonding operation.

Regarding this second application. the laser shock adhesion test approach is identified as a technique of lùgh potential The laser shock wave technique applied to the adhesion test was flrst developed byJ.L Vossen $(13,14)$.Based on shockwave propagation induœd by laser irradiation, this technique can create a short but intense internai tensile loading. The LAser Shock Adhesion Test (I.ASA1) aim is to enable the assessment of the bond mechanical perfonnanœ in a non-destructive test approach by creating a predse tensile load at the bondline-substrate interface. The 
concept of use for this technique makes it a non-destructive test for an optimal bond, but destructive if the bond does not meet the requested adhesive bond strength, which shall then be specified as design criteria. The I.ASAT technique has already been developed for metal assemblies or metal coatings, for which it is now weil understood $(15,16]$. For example, the technique bas been studied for the adhesion of aluminum assemblies [17,18]. These studies have shown the importance of the laser parameters for the test efficiency. Conceming composite materials, sorne studies are currently conducted in order to understand the composite behavior under a laser loading [19,20]. Under sorne conditions, the I.ASAT technique bas already been tested on different composite assemblies [21-23]. Nevertheless, more investigations remain necessary in order to optimize the technique and to better understand the associated complex pbysical phenomena.

In this paper, the potential of the laser shock adhesion test on weak composite bonds is studied. The fucus has been made on the production of controlled weak bonds as weil as on the onderstanding of the bonded composite response to laser shock loading. It is based on CFRP samples manufactured with adherend surface contamination by mold release agent and contaminated peel-ply for the generation of weakened adhesive bonds. The present paper introduces the steps in the production of relevant samples and their characterization with use ofUltrasonic Testing, X-Ray Photon Spectroscopy and mechanical testing by double cantilever bearn test $G_{1} c$ to finally enable correlation with the subsequent laser shock results. As a second step, laser shocks were performed on both uncontaminated and contaminated bonds. The effects of the laser shock wave propagation have been studied using two postmortem techniques: cross-section observations and interferometrie confocal microscopy. The correlation between the laser parameters and the resulting damage inside the composite assemblies is studied. Finally, the potential of the laser shock technique to discriminate different bonding qualities is shown and the need for the optimization of the I.ASAT technique is discussed.

\section{Sample preparation}

\subsection{About weak adhesive bonds}

The optimal development of a technology able to assess the quality of adhesive bonding in CFRP structures is relying on the capacity of manufacturing different levels of adhesion on purpose. For this matter, methods and experiences can only be scarœly derived from the literature which mainly focuses on bonding of metallic substrates and ageing of adhesive joints. Three main criteria for the definition of a weak bond are however given by Marty et al. [3]: (i) The strength measured by mechanical test must be below $20 \%$ of the nominal bond strength; (ii) The mode of failure must be adhesive in type (i.e. purely at the interface between the adherend and the adhesive); (iii) The weak bond must be undetectable from normal bonds with classical NDT techniques. These criteria are considered in this study and define the target for the specimen manufacturing.

In the frame of this study, a realistic approach close to the challenges of manufacturing and in-service for aerospaœ industry consists in modifying surface chemistry to influence the adhesion quality. On CFRP parts, if a contamination is not detected and treated, it will interact with the adherend and/or adhesive and so affect the quality of the joint [24].Surface contamination can occur during production or during repair due to process deviations (e.g. residues of mold release agent), fluids (e.g. silicone oit, de-icing fluid, hydraulic fluid) or by other original organic substances [25]. ln this paper, the contamination is applied on the substrate prior to bonding, in opposition to other approaches using the modification or alteration of the adhesive properties itself [26,27]. The contaminations selected for this study are based on most aerospace relevant investigated parameters by Marty et al., Wachinger et al. andjeenjitkaew et al. $[3,12,28]$.The first technique consists in applying a thin layer of a silicone-based mold release agent, the Frekote 700 NC. on the adherent surface prior to bonding. Frekote 700 NC involves PDMS (polydimethylsiloxane) which can leave traces during manufacturing of the composite substrate. This type of contamination can appear in cases of CFRP molding processes and prevents any efficient further operation on the composite surface. In the case of a known contamination, a surface cleaning process (e.g.: grinding, solvents or UV exdmer lamp) and/or activation treatment (e.g. Low pressure atmospheric plasma) can be applied $[24,29]$.The second method of contamination realized in this paper is based on the use of a contaminated peel-ply during manufacturing. The peel-ply PFG 51789 Super release Blue (SRB) bas already demonstrated in the last decade a strong predisposition to surface contamination through traces of its polysiloxane coating, as weil as fluorine attributed to the transfer of the fluorinated hydrocarbon coating from the peel-ply to the substrate [30].Both approaches will therefore be considered to manufacture weak adhesive bonds in CFRP, and evaluate to which extent their influence can reduce the bondline strength.

\section{Manu.\{acturing process}

Composite samples were manufactured with the 180 oc curing temperature system T800S/M21 (Hexcel Composite). The panels are prepared with a dry peel-ply to master surface deanliness and roughness as recommended by Airbus process specification. Laminates of 6 plies $[0,0,90] \mathrm{s}$ were produced in order to reach a thickness of $1.5 \mathrm{~mm}$ for a single cured panel, and so finally approximately $3 \mathrm{~mm}$ after the bonding operations. The $3 \mathrm{~mm}$ thickness is required as a standard for the mechanical characterization tests applied to evaluate the bond strength. The laminates were cured in an autoclave with the specified Airbus cure cycle, with use of pressure and vacuum. The laminates of $1.5 \mathrm{~mm}$ were inspected by ultrasonic testing after the curing to ensure the structure integrity of the substrates. This step was performed successfully, so that no defect was revealed by the ultrasonic scans. The surfaces of the laminates produced were not additionally treated after the curing step, only the peel-plies on the surface were removed prior to bonding or contamination operations. The first contamination by mold release agent was brought on the surface of another single laminate substrate by dip-coating. The dip-coating process bas the advantage of being a velocity controlled immersion, which enables the deposit of a homogenous contaminant layer over the substrate surface. In this feasibility study, no contamination grades are however targeted, but only the two extreme cases of uncontaminated and weak bond. The contamination is therefore applied with a concentration of $20 \%$ of Frekote diluted in hexane solvent Hence, the contaminated panel is dried for $30 \mathrm{~min}$ at room temperature and $60 \mathrm{~min}$ at $80 \mathrm{OC}$ in an oven with air circulation. The second contamination with contaminated peel-ply was applied directly during the manufacturing step. Specifie laminates were produced with use of the super release blue peel-ply instead of the standard dry peel-ply. The contaminant is thus brought on the surface during the curing step of the composite laminate and remains after the peeling of the peel-ply afterwards. No additional steps are required for this contamination.

After the contamination of one adherent surface, the bonding operation is performed with a Cytec epoxy adhesive film FM300 K $180 \mathrm{OC}$ system and another pre-cured larninate in the uncontaminated state. The contamination is thus only present on the whole 
surface of a single adherent laminate within the adhesive bond sample. This 'secondary bonding' process - the assembly of two pre-cured composite - is performed in an autoclave with use of pressure and vacuum. The final steps of manufacturing were to prepare the samples for the post-bonding characterization: (i) the bonding operation success by conventional NDT inspection; (ii) the mechanical performance by determination of fracture toughness; (iii) the potential of laser shock adhesion test. The samples were cut out of the bonded panels so that a single panel provides samples for the tests i, ii and iii and so, enable an optimal comparison based on a 'single shot' manufactured sample.

\subsection{Characterization of samples}

\subsubsection{X-Ray photon spectroscopy}

Prior and after the Frekote solution contamination, the sample surfaces were characterized by X-Ray photon spectroscopy (XPS) to analyze the atomic composition of the substrate top surface. The XPS technique is used to evaluate the presence of silicon and with it, to prove a contamination of the surface. Measurements are conducted locally at two different regions from the laminates and the values given in Table 1 represent the average of those two measurements. Results present first the composition of the uncontaminated sample surface, corresponding to a standard epoxy resin, with a high rate of carbon, oxygen and nitrogen. Measurements on the contaminated samples exposed to the Frekote solution revealed in addition to those elements a stronger concentration of oxygen and a high silicon amount (18.3 at\%) on the composite surface. From this result, it was stated that the PDMS of the release agent had released traces on the composite substrate. The XPS data from the specimen manufactured with the SRB Peel-ply was also showing a slight increase of the silicon rate at the surface, with on top of it a strong signal due to fluorine (28.7 at\%), as well as low values of calcium and sodium. The high value for the fluorine was expected and confirms the observations cited in the literature by Parker et al. [30-33]. For both contaminated specimens, the lower rates of carbon and nitrogen may be due to the presence of a masking uniform layer of contaminant on top of the epoxy resin. Based on the XPS data, it could be stated that both contaminations with release agent Frekote and SRB peelply were applied successfully to the composite substrate. The contaminated laminates were then used for the adhesive bonding process.

\subsubsection{Ultrasonic inspection}

After the bonding process with a clean laminate, the bonded panels were again inspected by ultrasonic techniques (UT) to ensure the absence of physical defects such as pores, debondings and delaminations in the adhesive bond, but also to evaluate if a weak bond condition could be detected by means of conventional NDT, as defined in Section 2.1. The UT inspection was performed according to the Airbus Test method AITM 6-0045 for the inspection of structure with UT techniques in immersion. The pulse-echo mode was used with a focused probe Olympus V309F operating at $5 \mathrm{MHz}$ and with a beam width of $12.7 \mathrm{~mm}$. The step size is of $2 \mathrm{~mm}$ and no time corrected gate (TCG) is applied. The bond line and the backwall echoes are represented in Fig. 1a for the uncontaminated panel (LA), and the contaminated samples with Frekote (LB) and SRB peel-ply (LE). All intermediate echoes at the bondline are similar and do not show any attenuation that could be inherent to any defect or contamination. The backwall echo in the case of the Frekote features a higher attenuation than uncontaminated and SRB peel-ply contamination. The values of attenuation are referenced in Table 2. Additional UT tests with UT phased-array were conducted to investigate this attenuation effect. The LB panel was inspected from both sides and it could be stated that the high concentration of Frekote present on the contaminated substrate layer was clearly appearing on this particular interface, forming a slight barrier. The detection of Frekote was however not expected and with regard to the literature versus this particular case, is assumed to be possible only in the case of high concentration, which is not likely to happen during standard manufacturing processes in the industry.

\subsubsection{Double cantilever beam test}

The mechanical characterization of the bonded panels was based on the evaluation of the bondline strength to enable correlations with the LASAT results. For this purpose, a double cantilever beam test $G_{1 \mathrm{c}}$ was performed according to the Airbus norm AITM 1-0053 with 6 samples of each bonded state (see in Fig. $1 \mathrm{~b}$ and c). The specimens' dimensions are $250 \times 25 \times 3 \mathrm{~mm}$. A crack initiation was applied to the DCB specimen perpendicular to the adhesive bond line plane through the use of piano hinges under a constant rate of displacement. The tensile strength is applied in the mode I, perpendicular to the crack plane which hence loads the bond line. The crack propagation and the according load are recorded until a crack length of around $110 \mathrm{~mm}$ from the initial crack is reached. The fracture toughness $G_{1 C}$ is then calculated based on Eq. (1) where $A$ is the energy to achieve the total propagated crack length in $J$ (integration under the curve), $a$ is the propagated crack length after crack initiation in $\mathrm{mm}$ and $w$ is the width of the specimen in $\mathrm{mm}$.

$G_{1 C}=\frac{A}{a \times w} \times 10^{5}\left(\mathrm{~J} \_\mathrm{m}^{2}\right)$

The results of the $G_{1 \mathrm{C}}$ tests (see Fig. $1 \mathrm{~b}$ and c) reveal in general low mechanical performances even for the uncontaminated specimens $\left(298 \mathrm{~J} / \mathrm{m}^{2}\right)$. This can be explained by the high sensitivity of $G_{1 \mathrm{C}}$ to overaged prepreg or unclean peel-ply, knowing that the composite prepreg used for the manufacturing of the panels was close to its end of worklife. All values however respect the thumb rule of a standard deviation between $10 \%$ and $15 \%$ usually observed with $G_{1 \mathrm{C}}$ tests. The rupture profiles of the adhesive bond represented in Fig. 1b are all adhesive for all three series of samples LA, LB and LE. The performances are however still highly influenced by the presence of contaminant with significant drops of the bondline strength for LB and LE series respectively corresponding to a $78 \%$ and a 93\% loss from the uncontaminated. Thus, these series form a set of samples interesting for the laser shock test.

\subsubsection{Summary}

The process of contaminations was successful in reducing drastically the adhesive bond performance in mode I for the Frekote LB and SRB Peel ply LE specimens. Their low adhesive bond strength

Table 1

XPS results for the uncontaminated and both contaminated samples.

\begin{tabular}{|c|c|c|c|c|c|c|c|c|}
\hline & $C(\mathrm{at} \%)$ & $\mathrm{O}$ (at\%) & $\mathrm{N}(\mathrm{at} \%)$ & $\mathrm{S}(\mathrm{at} \%)$ & $\mathrm{Si}$ (at\%) & $\mathrm{F}(\mathrm{at} \%)$ & $\mathrm{Ca}(\mathrm{at} \%)$ & $\mathrm{Na}$ (at\%) \\
\hline Uncontaminated LA & 72.8 & 15.9 & 10.1 & 1.0 & 0.3 & - & - & - \\
\hline Frekote LB & 51.2 & 27.8 & 2.5 & 0.2 & 18.3 & - & - & - \\
\hline SRB Peel-ply LE & 54.3 & 11.5 & 1.6 & 0.6 & 3.0 & 28.7 & 0.2 & 0.1 \\
\hline
\end{tabular}


a

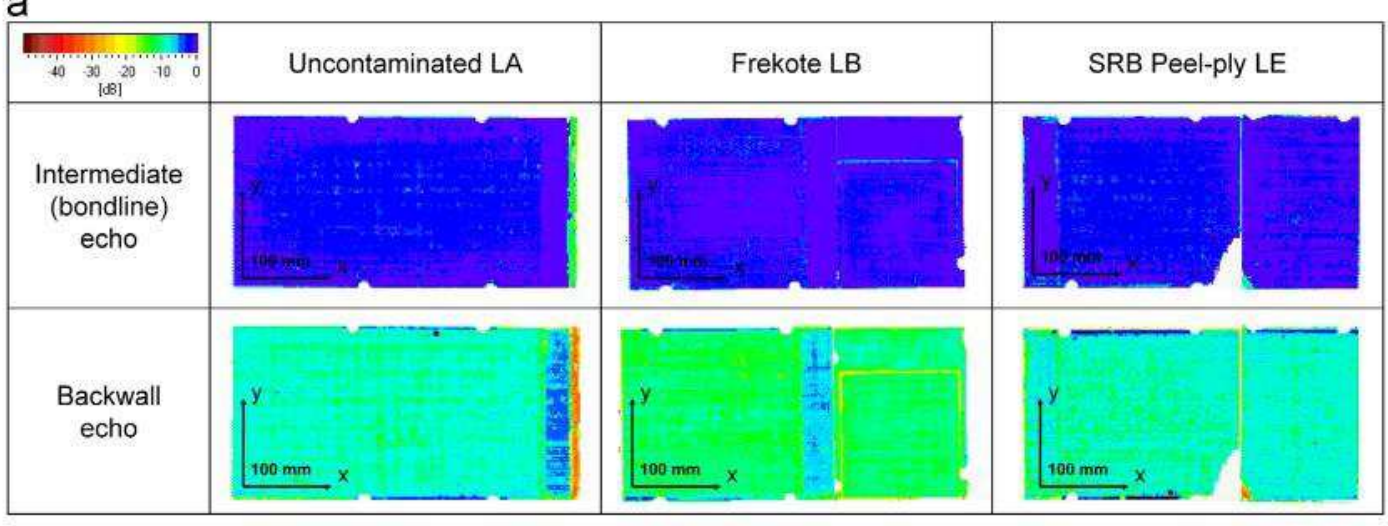
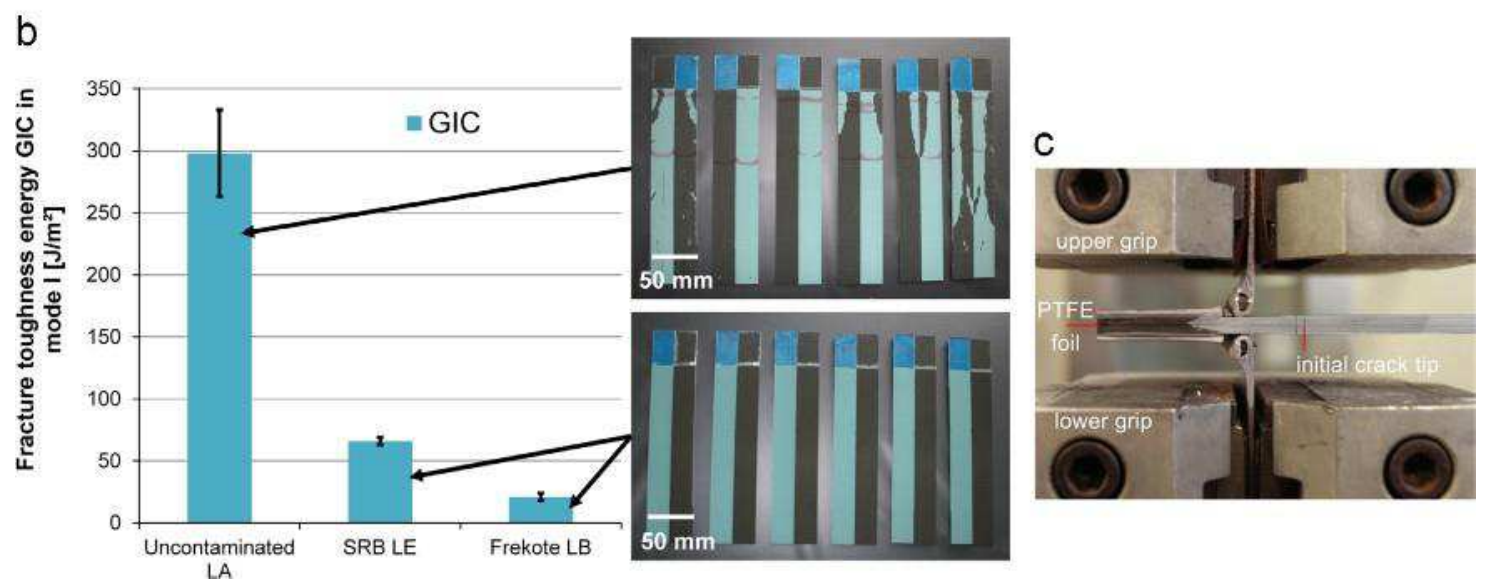

Fig. 1. (a) Ultrasonic C-scans of bonded panels uncontaminated (LA), Frekote contaminated (LB) and SRB Peel-ply (LE) displaying UT echoes at bond line and backwall, (b) fracture toughness energy $G_{1 C}$ of LA, LB and LE samples with according sample rupture profiles and (c) $G_{1 C}$ specimen in testing machine.

Table 2

Measured average signal attenuation on both the intermediate and the backwall echo for bonded panels uncontaminated (LA), Frekote contaminated (LB), SRB Peelply contaminated (LE).

\begin{tabular}{llc}
\hline Plates & Intermediate echo $(\mathrm{dB})$ & Backwall echo $(\mathrm{dB})$ \\
\hline Uncontaminated LA & -2.2 & -9.3 \\
Frekote LB & -1.4 & -11.5 \\
SRB peel-ply LE & -2.0 & -9.3 \\
\hline
\end{tabular}

compared with the uncontaminated sample one, is relevant enough to enable feasibility tests with the laser shock adhesion technique on the produced specimens.

\section{LAser Shock Adhesion Test (LASAT)}

\subsection{Laser adhesion test principle}

The laser shock wave technique consists in a high power laser irradiation of a target surface. When focused on a material, the laser irradiation transforms the surface into a dense plasma gas. The expansion of the plasma created on the material surface produces a shock wave (see sketch in Fig. 2a, b). This incident shock wave propagates through the target thickness according properties depending on the multilayer material characteristics and geometry (see in Fig. $2 \mathrm{~b}$, step 1 ). When reaching the sample back face, the incident shock wave is reflected into a release wave propagating backward. Then, this release wave can cross the incident release wave coming from the front face and initiated by the end of the loading (see in Fig. 2b, steps 2 and 3 ). This second release wave can be understood as an unloading wave. It leads to local high tensile stresses which could damage the material if the local damage threshold is over passed. In case of Fig. 2a example, the tensile stresses resulting from the laser shock wave propagation have led to a large delamination in the tested T800S/M21 composite. A higher level of damage would be characterized by the spallation of the material target. Indeed, the resulting tensile stress level is directly linked to the laser shock amplitude whereas its location mainly depends on the material properties and the pulse characteristics. As shown in the time/position diagram presented in Fig. $2 c$, the position of the maximum tensile stress is mainly determined by the laser pulse duration. For a given material and a given geometry, a short pulse (10-50 ns) would locate the first tensile stresses close to the back face like in Fig. 2a (about 20 $250 \mathrm{~m}$ ), when long pulses (100-300 ns) could locate the stresses deeper inside the target (about $500-1500 \mathrm{~m}$ ). In case of laser shock adhesion test, the optimized case occurs when the tensile stresses are located around the bonded interface to be tested. Then, the pulse duration remains unchanged and the laser energy can be tuned to evaluate the damage threshold of this interface by changing the stresses amplitude. Therefore, the bonding quality can be assessed and different levels of adhesion can theoretically be discriminated.

\subsection{Laser test campaign}

\subsubsection{Experimental con guration}

The bonded composite samples are first prepared using an aluminum coating on the front face, to enhance the interaction with the laser. Then, they are shocked with various laser energy levels to produce different levels of inside damage, using a water 
a

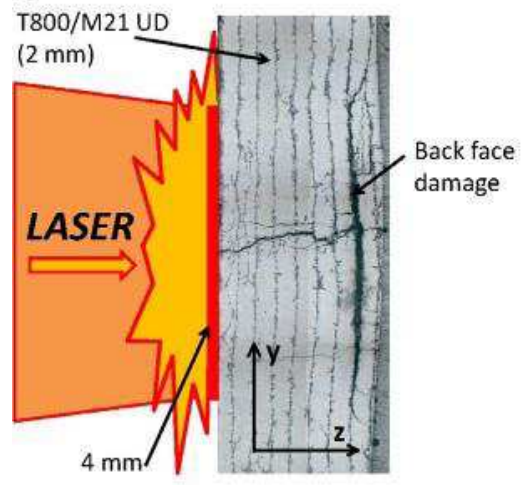

b

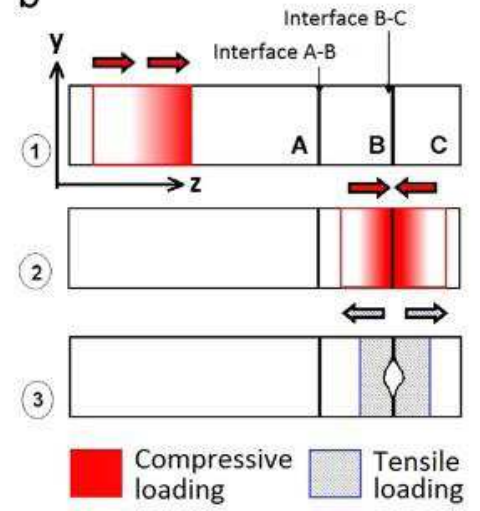

C

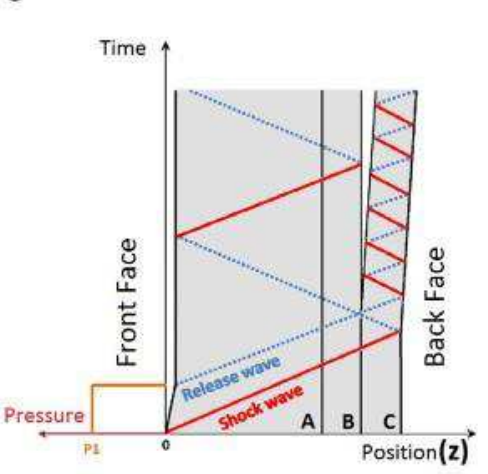

Fig. 2. (a) Sketch of the laser shock wave method with a shocked T800/M21 unidirectional composite material ( 2 mm thick, water confined laser pulse $I=2.11 \mathrm{GW} / \mathrm{cm}$ ), (b) sketch of the wave propagation history, (c) time/position diagram showing a one-dimension shock wave propagation history in case of spallation.
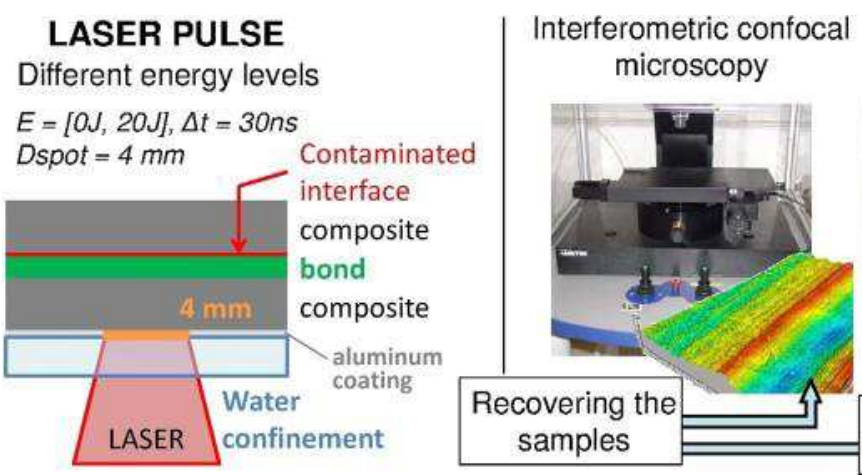

Optical Micrographies

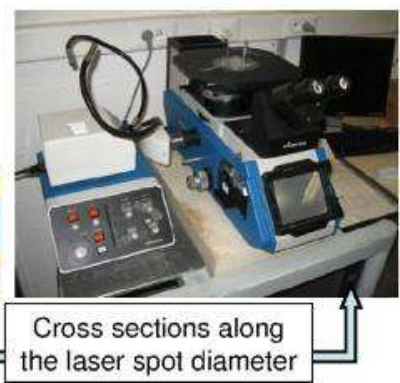

Fig. 3. Sketches of the laser shock experimental configuration and of the followed experimental procedure to test and analyze the bonded composites.

Table 3

Laser shock parameters used on bonded composite samples - All the shocks were water confined and performed with aluminum coating on the targets.

\begin{tabular}{|c|c|c|c|c|}
\hline Samples & $\begin{array}{l}\text { Focalized diameter } \\
(\mathrm{mm})\end{array}$ & $\begin{array}{l}\text { Pulse duration } \\
\text { (ns) }\end{array}$ & $\begin{array}{l}\text { Laser } \\
\text { energy (J) }\end{array}$ & $\begin{array}{l}\text { Intensity } \\
(\mathrm{GW} / \mathrm{cm})\end{array}$ \\
\hline LA-1 & $4_{7} \quad 0.1$ & $26.7,0.2$ & $7.8,0.1$ & $2.31,0.10$ \\
\hline LA-2 & $\begin{array}{ll}4_{7} & 0.1\end{array}$ & $25.4_{7} 0.2$ & 5.470 .1 & $\begin{array}{ll}1.78 & 0.17\end{array}$ \\
\hline LA-3 & $\begin{array}{ll}4_{7} & 0.1\end{array}$ & 27.970 .2 & $\begin{array}{lll}3.7 & 0.1\end{array}$ & 1.0670 .10 \\
\hline LB-1 & $4_{7} 0.1$ & $24.7_{7} 0.2$ & $\begin{array}{lll}7.9 & 0.1\end{array}$ & 2.5570 .20 \\
\hline LB-2 & $4_{7} 0.1$ & $26.7_{7} 0.2$ & $3.3_{7} 0.1$ & $0.98_{7} 0.10$ \\
\hline LB-3 & $\begin{array}{ll}4 & 0.1\end{array}$ & $26.0_{7} 0.2$ & 0.770 .1 & 0.2170 .02 \\
\hline LE-1 & $\begin{array}{lll}4 & 0.1\end{array}$ & $27.0_{7} 0.2$ & $7.6_{7} 0.1$ & $2,2470.20$ \\
\hline LE-2 & $4_{7} 0.1$ & $24.2_{7} 0.2$ & 3.370 .1 & $1.08_{7} 0.10$ \\
\hline LE-3 & $4_{7} 0.1$ & $27.3_{7} 0.2$ & $1.6_{7} 0.1$ & $0.48_{7} 0.05$ \\
\hline
\end{tabular}

confinement configuration in order to increase the pressure level. A sketch of the experimental configuration is given in Fig. 3. A Nd. YAG laser (1053 nm wavelength) whose energy is tunable in the range $[0-20 \mathrm{~J}]$ was used. Optical densities were used to change the laser energy sent on target and so, the laser intensity. The source pulse duration is about $30 \mathrm{~ns}$, which leads to an induced pressure pulse about $60 \mathrm{~ns}$ because of the water confinement as shown by the work of R. Fabbro [34]. The laser parameters measured for each tested sample are presented in Table 3 with the associated uncertainties. After the shock, the samples are analyzed with two different setups as shown in Fig. 3. Interferometric Confocal Microscopy (ICM) on the sample back face was used to quantify the out-of-plane back face residual deformation such as height variations (topography). Optical micrographs of sample cross sections were also performed to observe the inside damage resulting from the laser shock wave propagation.

\subsubsection{Main damage description}

A representative overview of damage resulting from laser shock on a bonded composite is given in Fig. 4. In this work, micrographies and ICM measurements are presented according the following codes (Figs. 4-7). The cross sections were performed perpendicularly to the $0^{\circ}$ direction. The observed damage was enhanced using white lines. The ICM measurement gives an image of the sample out-of-plane back face residual deformation. The $z$ deformation height is represented by the color scale, where purple is referring to non-measured points (due to roughness or out of range height). The sample presented in Fig. 4 is extracted from the LB contaminated series. Three main types of damage can be observed:

(i) Delamination between the plies: they are initiated by the high tensile stresses generated by the propagation of the laser induced shock waves inside the composite. Indeed, with the used laser source, the crossing of release waves occurs close to the sample back face. Thus, the high tensile loading starts in this region, and exceeds the composite damage threshold in this case, inducing delamination. On the micrography (Fig. 4), it can be observed that the delamination took place between $90^{\circ}$ and $0^{\circ}$ plies. The delamination width in the $90^{\circ}$ direction (cross section plan) corresponds to the focal diameter of the laser spot. Thanks to the residual back face deformation measurement by ICM, it has been evidenced that this delamination propagated in the $0^{\circ}$ direction. It is characterized by the elliptical blister oriented in the $0^{\circ}$ direction (see ICM in Fig. 4).

(ii) Debonding of the bonded interface: this debonding was possible thanks to the tensile loading propagating backward from the back face to the front face after the crossing of release 


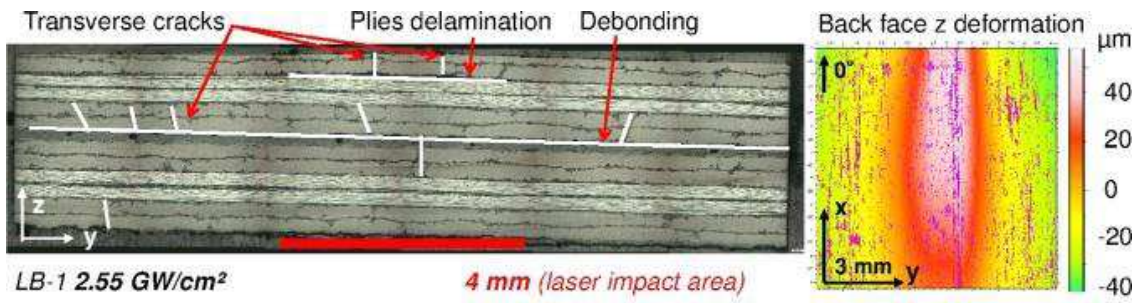

Fig. 4. Representative micrography and ICM height measurements of damage resulting from shock wave propagation inside a bonded CFRP with a low adhesion level LB-1.

waves. Even if some fracture energy was dissipated inside the composite to initiate delamination, enough energy remained to initiate the debonding. In this case, the stresses exceeded the bond interface damage threshold. The low adherence level helped to conduct to a full debonding as shown in Fig. 4. In the case of debonding, no clue of a favorite propagation direction was found by the ICM measurement.

(iii) Transverse matrix cracks, through the ply thickness: these cracks are mainly due to the bending component of the laser loading and occurred after the main damage initiation presented in (i) and (ii). Indeed, during the laser shock loading, the samples are held by their edges. These experimental conditions lead to a bending loading which is different from the shock wave loading, but also induces damage in the bonded composite.

To summarize, the laser shocks induce two main damage types in a weakly bonded composite, a delamination in the composite which is opposite to the laser shock loading and a debonding in the bond interface. This is possible only because the stresses generated in the composite by the waves are exceeding the composite damage threshold and the debonding threshold respectively.

\subsubsection{Contaminated bonded composite results}

The two contaminated series, referred LE and LB, were first investigated in this work. The aim of this investigation was to study the damage resulting from various laser shocks, in order to evaluate the potential of the laser shock adhesion test to evidence the presence of a weak bond. Thus, various intensity laser shocks were produced in the water confinement configuration, for each contamination. As previously explained, all the samples were studied by using ICM and cross section observations after the shocks.

Results obtained in case of LE contamination series are presented in Fig. 5a, in which three micrographies and two of the corresponding ICM measurements are presented. A correlation between the laser intensity and the inside damage extent is observed (see in Fig. 5a). In the cross section observations, a gradation in the level of damage can be seen from the lowest intensity level to the highest. Indeed, the lowest laser shock (LE-3) did not lead to any observable damage inside the bonded composite. Samples LE-2 and LE-1 analyses show respectively more and more cracks, as well as more sizeable delamination in the back face composite, and more sizeable debonding. The residual back face deformation measurements obtained by ICM also agree this trend. As it is shown in Fig. 5a, the lowest shock did not modify the LE-3 sample back face, which is consistent with the absence of delamination. In case of LE-2 sample, a small blister can be observed, corresponding to the inside delamination revealed by the micrography observation. Case of sample LE-2 is interesting. Indeed, the composite part of the assembly remained almost unharmed after the laser shock wave propagation (small residual deformation and delamination). This is probably due to the fact that the used laser intensity ( $\sim 1 \mathrm{GW} / \mathrm{cm}$ ) was low enough for the induced tensile stresses to be close to the damage threshold of the CFRP composite, meanwhile being high enough to open the bond line of the sample, whose damage threshold was even lower according to these observations. From results presented in Fig. 5a, it can be concluded that in these experimental conditions the debonding threshold of the LE series is between $0.48 \mathrm{GW} / \mathrm{cm}$ and $1.08 \mathrm{GW} / \mathrm{cm}$ and that its composite damage threshold is in the same range, but probably closer to $1.08 \mathrm{GW} / \mathrm{cm}$.

The results obtained in case of LB contamination series are presented in Fig. 5b, and agree with the observations made in case of samples LE. The correlation between the laser intensity and the damage extent has also been evidenced in the case of the LB contamination series. ICM measurement and micrographies are still consistent (see samples LB-1 and LB-2 in Fig. 5b). The results obtained in case of LB samples are really similar from the ones coming from LE samples. According the results presented in Fig. $5 \mathrm{~b}$, the LB series debonding threshold is in the range [0.21$0.98 \mathrm{GW} / \mathrm{cm}$ ] which is really close to what has been observed on LE samples. This could be explained by the small difference on the adherence level induced by the contamination. Indeed, even if the contamination process is very different from LB to LE samples, their consequences on the adhesion level have been identified by the GIC testing to be close to each other (see GIC test in Fig. 1b). Considering the uncertainties on the contamination process as well as the uncertainties on the produced laser shock, it would be difficult so far to distinguish these two contamination levels. With regards to the composite damage, the out-of-plane deformation (about $25 \mathrm{~m}$ high) observed by ICM on the LB-2 sample back face shows that the composite damage threshold is again closer to $1 \mathrm{GW} / \mathrm{cm}$. The contaminations in case of both LE and LB series have no reason to affect the composite part of the assembly, which can explain the similarity between the two composite delamination thresholds. The composite being the same, it is logical that the induced laser shock damage is also the same for a given intensity in the different samples.

This last point has been clearly evidenced by extracting back face deformation profiles from the ICM measurements, in order to compare the composite part damage extent in both case of LE and LB contamination. The ICM profiles taken at the middle of each blister along the $y$ axis, are presented in Fig. 5c. The LB-3 and LE-3 samples received the lowest shock in each series, which did not lead to any observable damage. Their back face surfaces are thus completely flat. Regarding the laser uncertainties, it can be considered that LB-1 and LE-1, as well as LB-2 and LE-2 have respectively received the same laser loading. The back face deformations measured are similar in both cases as shown in Fig. 5c. The small differences observed can also be attributed to the experimental dispersion. The reproducibility of the laser technique used is also proved by this result.

\subsubsection{Uncontaminated bonded composite results}

In a second time, the uncontaminated series has been experimentally investigated, following the same protocol, and using the 


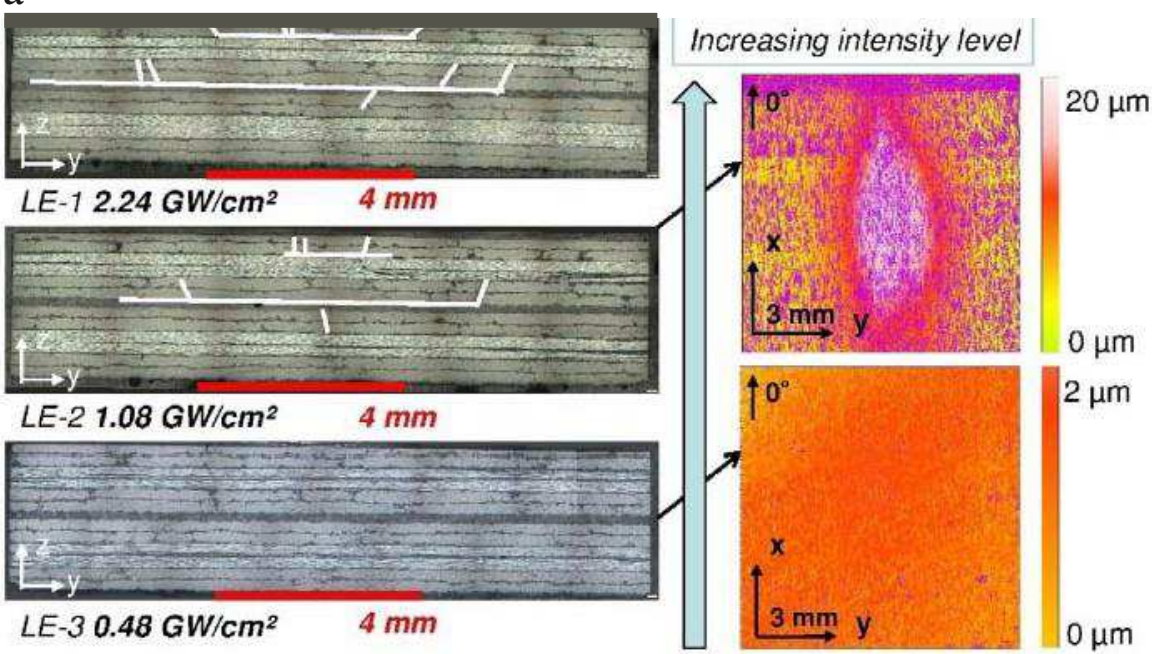

b

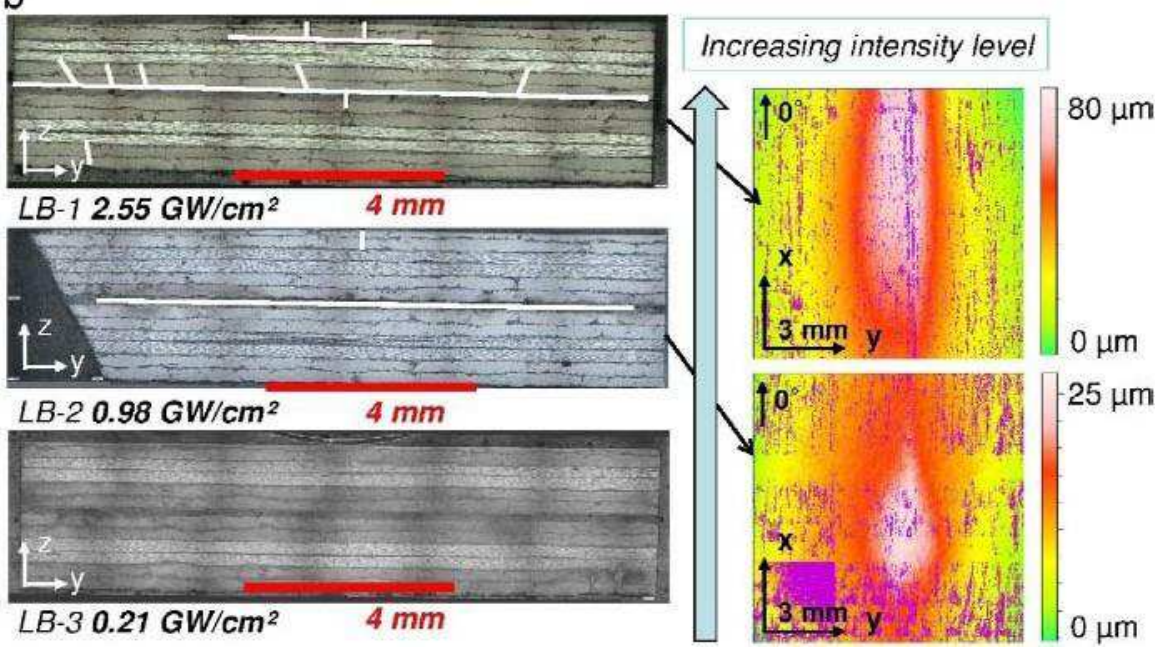

$\mathrm{C}$

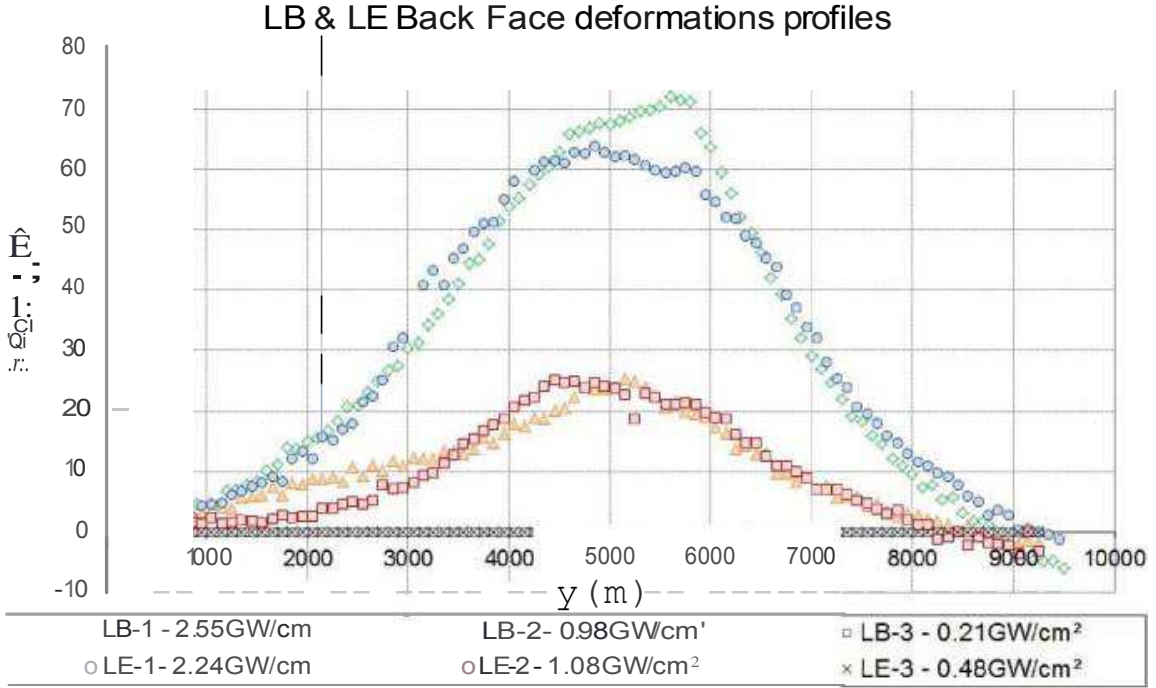

fil.5. Olaracterlzatlo of the dalnage exteDt lnto the boDded composite by micrographies and JCM 111 case of(a) LE series. (b) lB series. (c) comparison between the bacle faœ resldual deforuwions me.ISIII'eCI by !CM $\ln$ case Or LE ao.d IB series tor three dlft'erent Laser Intensitles.

same tools. The characœrization of the damage resulting from the laser shock wave is also carried out. Results are presenœd in Fig. 6. The main difference with bath $œ$ and $l B$ series is the absence of debonding for none of the generated shocks, even the highest intensity one. For this uncontaminated sample. the tensile stresses generatEd by the laser shock wave propagation were not high enough compared to the debonding threshold of the uncontaminatEd bond interface. Nevertheless, the transverse aacks and the 


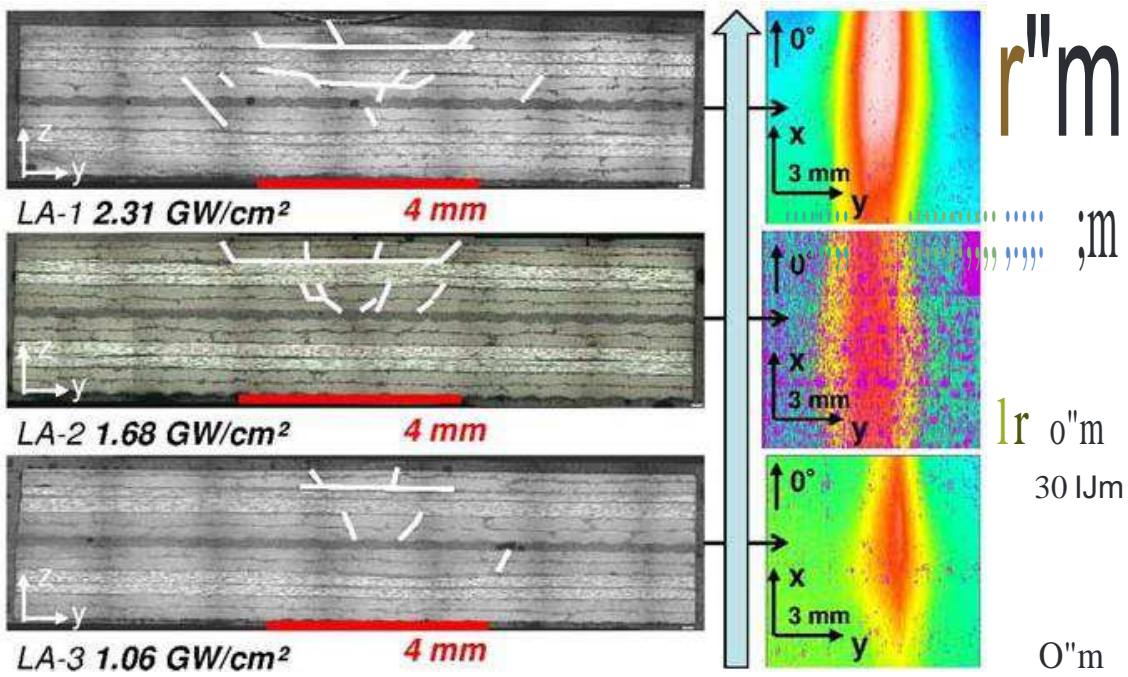

Fis. 6. COrrelation between the laser Inœnslty and the dacnaae extent !niD the bonded composite materlal observecl by mla'ol(raph.les and musutec 1 by ICM Incase of LA serieL
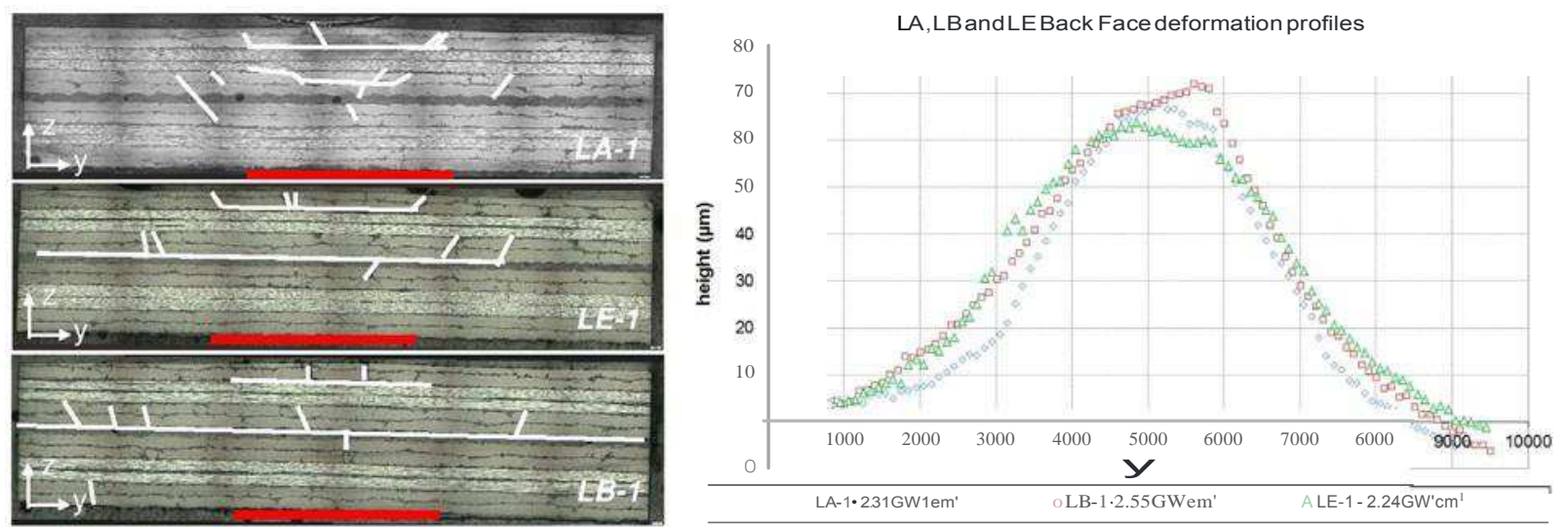

$f^{\prime} \mid$ 3. 7. Comparison between a correctly boru1ed iiSSeinbly (LA ) and two wealc bond s.amples (LB and $\mathbb{E}$ ) by use of cross smion observations i1DCI ICM measurements.

induced delamination in the composite part of the assembly are still present. The correlation between the laser intensity and the damage extent is also shown in this case, by the cross section miaograplùes as weil as by the ICM measurements. The composite damage threshold is also close to the ones evaluaœd on the previous contaminated series whlch is logical slnce the contamination does not influence the composite quality.

\section{Discussions}

ln Fig. 7.the results from the samples of different adhesion degrees are presented The uncontaminated sample IA-1 is presented as weil as the weak bond samples lB-1 and 1.E.-1. Considering the experimental dispersion. it can be considered that the same laser shocks were perfonned on each sample (about $23 \mathrm{GW} /$ $\mathrm{cm}[$ ). This is confinned by the resldual back face deformation measurements, which show a correct agreement between each other. Jn the case of the uncontaminated bond, the laser shock propagation did not lead to a debonding whereas the same shock induces damage in the weak bonds presenœ. The potential of the laser teduùque to discriminate different bond qualities is thus proved by this result Indeed. if keeping in mind the proof test airn. the laser shocks produced on LE. and IB samples enable to discriminate their bonding quality compared to $1 \mathrm{~A}$ samples. Nevertheless, in each case. the composite part of the assembly was delaminaœd by the high tensüe stresses, on the bacle side.
This observation is confirmed by the ICM measurements also presented in Fig. 7:the bade face residual deformations measured on the three samples are significant For the laser shock wave adhesion test objective, it means that the performed laser shocks were not optimized for the test of the bonded interface. Indeed, the composite damage ls due to the fact that the maximum of tensile stress is generated close to the sample bade face. This is especially due to the shortness of the laser pulse, forcing the crossin, $\mathrm{g}$ of release waves in the last composite plies. Thus. these results show that the laser configuration was not enough adapted to the tesœd assemblles. They lndicate that the development of the laser adhesion test requites the optimiz.ation of the laser parameters, in order to localize the tensile loading at the bonded interface and so. avoid the creation of damage in the composite parts wlùle testing correct bonds. This optimization needs the use of new laser sources and/or new shock configurations. Work is $\ln$ progress to develop such original experimental setup. Once the laser parameters will be optimized. the laser shock wave adhesion test may be reali.zed without creating any damage in the composite parts. and thus, it could be used as a NOT method in order to disaiminate weak bonds from correct bonds.

\section{S. Condusloos}

The aim of this paper was to perform a feasibility study on the use of laser shock technique as an extended NOT method to 
evaluate the adhesion strength in composite assemblies. At first, a specific process of generating on purpose weak adhesive bonds has been developed. It is based on composite surface contamination with dip-coating in release agent and use of contaminated peel-ply during manufacturing. The conventional non-destructive characterization prior to laser shock test did not highlight significant differences between the uncontaminated and contaminated samples, while the mechanical GIC tests have shown a loss of adhesive bond performance about $78 \%$ and $93 \%$ compared to the uncontaminated sample value. The laser shock test method has thus been performed on these contaminated and uncontaminated series.

Results have demonstrated that it was possible to discriminate the different adhesion qualities with the laser shock method. It has also been shown that, with the used laser configuration, the generated maximum tensile stresses are located inside the composite instead of in the adhesive bond line. It leads to the creation of damage inside the composite parts, which has to be avoided for the laser adhesion test to be efficient. Therefore, new laser sources and/or configurations have to be developed in order to obtain a non-destructive laser adhesion test.

\section{References}

[1] Cognard P. Collage des composites, Secteur aéronautique. Techniques de l'ingénieur, traité Génie Mécanique. Editions T.I.; 2010.

[2] Stoeven T. Rivetless Aircraft Assembly - a dream or feasible concept EUCOMAS European conference on materials and structures in aerospace Berlin; 2010.

[3] Marty PN, Desaï N, Andersson J. NDT of kissing bonds in aeronautical structures, s.l.: CSM Materialteknik AB. Sweden: Linkoping; 2004.

[4] Adams RD, Cawley P. A review of defect types and nondestructive testing techniques for composites and bonded joints. NDT Int 1988;21:208-22.

[5] Light GM, Kwun H. Nondestructive evaluation of adhesive bond quality: state of the art review. San Antonio, Texas: Nondestructive Testing Information Analysis Center San Antonio Tx. Report no.: SwRI Project 17-7958-838; 1989. p. $1-10$.

[6] Adams RD, Drinkwater BW. Nondestructive testing of adhesively-bonded joints. NDT \& E Int 1997;30.2:93-8.

[7] Baumann J, Netzelmann U. Zerstorungsfreie Prüftechniken für Materialverbunde. Report no.: ISSN 0948-1427; 2003.

[8] Valeske B, Bockenheimer C, Henrich R. New NDT approach for adhesive composite bonds. NDT Appl 2008;1:203-9.

[9] Bockenheimer C. Novel approaches to non-destructive CFRP bond quality assessment. SAE 2011 AeroTech Congress \& Exhibition, Toulouse, France; 2011.

[10] Markus S, Tornow C, Dieckhoff S, Boustie M, Ecault R, Berthe L, et al. Extended non-destructive testing of composite bonds. SAE International; 2011. Report no.: 2011-01-2514.

[11] Ehrhart B, Valeske B, Chobaut N, Sarambe M, Gendard A, Bockenheimer C Preliminary tests for the development of new NDT techniques for the quality of adhesive bond assessment, Bremen, Germany: DGZfP; 2011.

[12] Wachinger G, Thum C, Llopart L, Maier A, Wehlan H, Stoven T. New trends in CFRP treatment and surface monitoring for automated structural adhesive bonding. In: Proceedings of the international conference on composite materials ICCM17, Edinburgh; 2009.
[13] J.L. Vossen, Measurements of film-substrate bond strength by laser spallation. ASTM special technical publication 640, Philadelphia, PA, USA, 1978, pp. 122 133.

[14] Yuan J, Gupta V. Measurement of interface strength by the modified laser spallation technique. I. Experiment and simulation of the spallation process. J Appl Phys 1993;74:2388-97.

[15] Braccini M, Dupeux M. Mechanics of solid interfaces, ISTE and Wiley eds.; 2012.

[16] Berthe L, Arrigoni M, Boustie M, Cuq-Lelandais JP, Broussillou C, Fabre G. Stateof-the-art laser adhesion test (LASAT) Nondestruct Test Eval. 2011:26:303-17.

[17] Laporte D, Malaise F, Boustie M, Chevalier JM, Buzaud E Thessieux C. Dynamic behaviour of two adhesive materials presented at the 18th DYMAT technical meeting, Strasbourg, France; 2010.

[18] Laporte D. Analyse de la réponse d'assemblages collés sous des solicitations en dynamique rapide, PhD defended at ENSMA, France; 2011.

[19] Ecault R, Boustie M, Touchard F, Berthe L, Chocinski L, Ehrhart B, et al. Damage of composite materials by use of laser driven shock waves, presented to the 26th annual technical conference/2nd Joint US-Canada conference on composites, Montreal, Quebec, Canada; 2011.

[20] Ecault R, Boustie M, Touchard F, Pons F, Berthe L, Chocinski L, et al. A study of composite material damage induced by laser shock waves. Composite Part A 2013:17.

[21] Bossi R, Housen K, Walters C, Sokol D. Laser bond testing. Mater Eval 2009;67:819-27.

[22] Perton M, Blouin A, Monchalin J-P. Adhesive bond strength evaluation in composite materials by laser-generated high amplitude ultrasound. J Phys: Conf Ser 2011;278.

[23] Boustie M, Gay E, Berthe L, Arrigoni M, Radhakrishnan M, De Résséguier T, et al., LAser Shock Adhesion Test (LASAT) of composite materials for aerospace industry, presented at the 23rd international conference on Surface Modification Technologies (SMT23); 2-5 Nov 2009, Chennai, India.

[24] Mueller-Reich C, Wilken R, Kaprolat S. Bonding of plastics: well-bonded despite residual release agents. Adhes Adhes Sealants 2011:3/2011:36-41.

[25] Brotherhood C], Drinkwater BW, Guild FJ. The effect of compressive loading on the ultrasonic detectability of kissing bonds in adhesive joints. J Nondestruct Eval 2002:95-104.

[26] Jastrzebski M, Sinclair A, Spelt J. Mechanical and industrial engineering Development of adhesive bonds with reduced strength as ultrasonic NDE benchmarks. Toronto, Canada; 2005.

[27] Barroeta-Robles J, Cole R, Sands JM. Development of controlled adhesive bond strength for assessment by advanced non-destructive inspection techniques. Seattle, WA: Society for the Advancement of Material and Process Engineering; 2010 (p. 15).

[28] Jeenjitkaew C, Luklinska Z, Guild F. Morphology and surface chemistry of kissing bonds in adhesive joints produced by surface contamination. Int J Adhes Adhes 2010;30:643-53.

[29] Ehrhart B, Valeske B, Ecault R, Boustie M, Berthe L, Bockenheimer C. Extended NDT for the quality assessment of adhesive bonded CFRP structures. Montreal, Quebec, Canada. Available from: international workshop smart materials, structures \& NDT in aerospace conference NDT in Canada; 2011.

[30] Parker BM, Waghorne RM. Surface pretreatment of carbon fibre-reinforced composites for adhesive bonding. Composites 1982;13:280-8.

[31] Parker BM, Waghorne RM. Testing epoxy composite surfaces for bondability. Surf Interface Anal 1991;17:471-6.

[32] Kim Jin Kook, Lee Dai Gil. Adhesion characteristics of plasma-surface-treated carbon fiber-epoxy composite with respect to release films used during demolding. J Adhes Sci Technol 2004;18(4):473-94.

[33] Parker Brenda M, Waghorne Rex M. Testing epoxy composite surfaces for bondability. Surf Interface Anal 1991;17:471-6.

[34] Fabbro R, Fournier J, Ballard P, Devaux D, Virmont J. Physical study of laser produced plasma in confined geometry. J Appl Phys 1990;68(no. 2):775-84. 